\title{
Life-lines of relapsed breast cancer patients : A study of post-recurrence distress and coping strategies
}

\author{
Ryoko TAGUCHI ${ }^{1}$, Yoshihiko YAMAZAKI ${ }^{1}$, Tomoko TAKAYAMA ${ }^{2}$ and Mitsue SAITO ${ }^{3}$
}

This study investigated latent distress and coping mechanisms existing in the experiences of relapsed breast cancer patients in order to identify strategies for improving support structures for this population. Semi-structured interviews were performed with 26 subjects receiving care from two medical facilities in the Tokyo Metropolitan area. In this study, the life-line methodology was selected as a tool to express the subjective QOL of subjects. Specifically, we used life-lines to examine the changing processes of the subjective QOL and to explore latent distress and coping mechanisms.

We found that 1) the life-lines of approximately half of the subjects regained a pre-initial diagnosis level of psychosocial equanimity after both the initial diagnosis of cancer and the first episode of recurrence ; however, the life-lines of some subjects remained depressed as they suffered multiple recurrences and a concomitant loss of hope, 2) relapsed patients faced an awareness of death and a sense of uncertainty, a decline in pleasures, and a declining ability to find meaning in life, 3) the recovery of the level of the life-line accompanied changes corresponding to a scale recalibration, a change in values, and a reconceptualization as described in response shift theory. These changes were confirmed in two areas : those related to sickness, treatment and survival, and those related to finding a significance in life itself and asserting one's reasons for living. Furthermore, as a result of cognitive coping strategies, the maintenance of life-line levels after recovery were attained in the same two areas as stated above, 4) when compared with a SF-8 survey methodology measuring a healthrelated QOL, the life-line methodology was more consistent with the mental health rather than the physical health domains, especially as related to identifying a personal meaning in one's life, and 5) relapsed patients combined characteristics of patients in both treatment and terminal stages of the disease.

Study results reinforce the recognition that relapsed breast cancer patients have an unmet need for support systems tailored to respond to their individual psychological characteristics.

Key words : breast cancer, recurrence, life-line, distress, coping, quality of life

\footnotetext{
${ }^{1}$ Department of Health Sociology, Graduate School of Health Sciences and Nursing, The University of Tokyo

${ }^{2}$ Cancer Information Service and Surveillance Division, Center for Cancer Control and Information Services, National Cancer Center

${ }^{3}$ Department of Breast and Endocrine Surgery, School of Medicine, The University of Juntendo
} 


\section{Introduction}

Since 1981, cancer has been ranked as the leading cause of death in Japan ; the rate of cancerrelated deaths continues to rise. The incidence of breast cancer is especially high, with notable increases in both morbidity (The Research Group for Population-based Cancer Registration in Japan, 2004) and mortality (Ministry of Health, Labour and Welfare, 2005). Such trends are expected to continue owing to a variety of factors, including a growing adoption of Western lifestyle habits.

With early diagnosis, the prognosis for breast cancer is generally good. However, about 30\% of patients experience recurrence, frequently with metastasis. In such cases, current therapies offer little hope for a complete cure.

Most women are stricken with breast cancer during the prime of life, when their contributions play a central role in the well-being of their family and the stability of society. A diagnosis of breast cancer is a devastating, life-altering event ; studies confirm that it precipitates a high degree of emotional distress, lifestyle disruption and reconstruction (Schnipper, 2001).

Some research reported in the literature indicates that a diagnosis of local or metastatic breast cancer recurrence causes even greater distress than a primary diagnosis (Mahon et al., 1990). Patients, aware of a diminished prognosis, experience uncertainty, fear of impending death, and loss of hope. They are faced with the continuation of ultimately futile therapies that also occasion severe side effects. Patients with disseminated metastases, in particular, suffer physical deterioration, limiting their ability to perform activities of daily living (ADL) and to benefit fully from supportive care (Oh et al., 2004). Among the most serious issues facing patients with recurring breast cancer are uncertainty, confusion regarding treat- ment options, coping with changes in roles and relationships with family, friends and medical personnel, and management of lifestyle transitions (Burnet and Robinson, 2000 ; Cella et al., 1990 ; Mahon and Casperson, 1997 ; Mahon et al., 1990).

Other studies suggest more positive outcomes in terms of health-related quality of life (QOL) and psychological adaptation among patients with relapsed breast cancer. A study by Bull et al. (1999) demonstrated significant resilience in the responses of 69 relapsed breast cancer patients. In their research, several domains of QOL indicators showed sharp declines immediately following diagnosis but substantial improvement in psychosocial functioninig at a six-month follow-up. In another study by Oh et al. (2004) comparing the QOL of matched samples of 54 recurrent and 54 non-recurrent breast cancer patients, both groups demonstrated similar, generally positive psychosocial adaptation at follow-up sessions in terms of health-related QOL indicators. These reports imply that improvements in $\mathrm{QOL}$ is seen in the areas of psychosocial functioning. However, more detailed components or adaptation processes are not treated explicitly.

A number of factors may explain the disparity among outcome results in studies of post-relapse psychosocial adaptation in breast cancer patients. Perhaps of greatest significance is the choice of psychosocial parameters selected for measurement (Oh et al., 2004). In addition to being easy to administer, the health-related QOL instruments used most frequently in clinical settings are designed primarily to assess the impact of physical and psychological factors on treatment effectiveness in clinical trials of therapeutic interventions. A more multi-dimensional assessment tool is necessary to yield a comprehensive assessment of the more subjective elements of a patient's QOL. Critics suggest inclusion of questions capable of 
addressing the existential/spiritual matters confronting patients facing death. An effective QOL instrument should include items to assess a patients' sense of the meaning of sickness, of her life, and of human existence (Belcher et al., 1989). To date, no such tool exists.

Study outcome disparities may also be influenced by a variety of complex factors particular to the lives of individual patients not reflected in the construction of standard QOL instruments. Issues that may have been important at one stage of a patient's disease may be irrelevant later on. Accordingly, a tool is needed that will permit patients to select QOL parameters most appropriate to their individual circumstances (Lawton, 1991).

Although an abundance of papers demonstrate that QOL assessment criteria have changed over time (Allison et al., 1997 ; Sprangers and Schwartz, 1999), that fact is rarely acknowledged in current studies. Further, studies of healthrelated QOL and psychological adaptation of breast cancer relapse patients have focused primarily on the mental status at the time of recurrence diagnosis (Bull et al., 1999). However, there is a paucity of research focusing on the process following recurrence with a progressive decline in physical and emotional health in the context of the demands of individual, family, and social life.

The intent of the current study is to delve into the processes and experiences of breast cancer patients after relapse using in-depth interviews which are not covered by existing study instruments and outcome measures.

One methodology that should be considered for evaluating QOL issues in these patients is designated variously as the life-line or the life graph. (Back and Averett, 1985 ; Martin, 1997 ; Schroots, 1996 ; Takkinen and Ruoppila, 2001). Life-lines are used to retrospectively plot chronologically personal histories and experiences as per- ceived by individual subjects to provide an overall visual representation of one's life. The method can be used either as an autobiographical data collection tool or as an aid in constructing a framework to organize recollections of personal events (Gramling and Carr, 2004 ; Schroots, 1996 ; Settersten and Mayer, 1997). By having respondents create their own visual representation, life-lines enable an integrated autobiographical review of the emotions and changes that have occurred thus far. Lifelines are fundamentally interpretive of the events they depict, so the result is inherently subjective (Gramling and Carr, 2004 ; Schroots, 1996). Because life-lines concentrate a multitude of experiences into a single line, they may be compared across groups according to specific characteristics including 1) rises, falls, stability, size and duration of changes ; and 2) averages and other patterns, yielding both qualitative and quantitative psychometric data for analysis. They have been used both as an interview tool and as a therapeutic instrument for treating both for individuals and groups (Settersten and Mayer, 1997). The life-line interview method may be used effectively with subjects of any age (Settersten and Mayer, 1997) ; however, it is chiefly used among geriatric and psychiatric populations (Gramling and Carr, 2004 ; Lewis and Butler, 1974 ; Martin, 1997). Although a search of the literature yielded no instances of application of the life-line method to relapsed breast cancer patients, it is deemed appropriate for the present study for several reasons :

- Life-lines aid in recollection of life events and life eras and so are appropriate for use in studies consistent with modern developmental theory, which emphasizes the contextual nature of experience (Gramling and Carr, 2004). Because the current study seeks to assess the impact of both breast cancer disease recurrence and subsequent long-term effects, the life-line methodol- 
ogy should work well.

- In contrast to above described methodologies, the life-line method is inherently longitudinal. Thus, it permits the multidimensional, dynamic construct of QOL expressed comprehensively as a single line. Accordingly, a holistic understanding of subjective respondent experiences may emerge.

- Using the life-line approach, standards implemented at the time of the interview are applied for the whole of the subject's life, thereby avoiding changes in standards over time (Blane, 1996 ; Schroots, 1996).

- The life-line method used in conjunction with interviews facilitates the interview process itself and deepens the relationship between interviewer and interviewee (Beaton, 1991). Thus, integrating the life-line method with actual interviews should yield better quality information than interviews alone (Jenks, 1995).

In the context of a rising incidence of cancer in general and breast cancer in particular, a significant proportion of patients will experience disease recurrence. Although disease relapse is generally considered incurable, medical advances offer increasing extended survival for such patients. Most will receive treatment on an outpatient basis. These facts underscore the importance of improving comprehensive support systems tailored to meet the needs of these patients.

Although there is consensus concerning the greater importance of improving QOL vs life extension in this patient population, little information is available concerning the subjective events of daily life that impact QOL ; likewise, few support systems address daily life issues outside of a clinical treatment context.

With these considerations in mind, the present study aims to analyze as comprehensively as possible 1) the process after a relapse of appropriate modification of subjective QOL criteria and 2) the application of data acquired by the life-line method to understand both latent distress and coping mechanisms employed by relapsed breast cancer patients. It is hypothesized that this approach will suggest effective strategies for improving support structures targeting this patient population.

To accomplish this goal, semi-structured interviews using the life-line approach were performed focusing upon the following points :

- What patterns emerge over the continuum of the interval before primary breast cancer diagnosis and extend through the post-recurrence period up to the time of this study? Especially, what types of changes resulted after relapse? Is there any correlation between the patterns of changes from primary diagnosis and the one from recurrence for each patient?

- What objective or subjective post-recurrence events or distress correlate with depressed lifeline patterns?

- How do patients cope with such adverse events or distress? How well do they recover?

\section{Methods}

\section{Subjects}

Study subjects included 26 women with breast cancer recurrence undergoing inpatient or outpatient treatment at one of two hospitals in Tokyo managed by specialists in the area of mammary and endocrine surgery. Subjects were selected with the aid of one surgeon from each of the two facilities. The subjects were recruited during a 7month period from January, 2004 to July, 2004. Inclusion criteria specified a minimum six month life expectancy based on the judgment of the physician. The exclusion criteria were that the physical condition was so severe that the patients could not participate in an interview and complete a questionnaire. Patients were approached initially 
by their physicians. If they consented to participate, then they were fully informed of the purpose, method, and procedure of the study by a researcher. The voluntary and confidential nature of the study was stressed. They were assured of their right to withdraw from the study at any time. Those who had agreed to participate provided written consent after reading an explanation of the study. The median period of medical treatment by the physician was 31 months (range : 1month to 176 months). About $70 \%$ of the subjects had seen the physician over 2 years. No patients who were approached declined to participate.

\section{Data Collection}

The nature of the study required eliciting extremely personal, emotionally-charged information from psychologically delicate subjects. For these reasons, the interview technique relied more upon empathetic, listening attentively but not intervening (Jenks, 1995 ; Kvale, 1996 ; Morse and Field, 1995). Furthermore, the past research on the interview methodology for the traumatized populations points out that it is important to give subjects enough time and quietness and not to force them to answer those questions that they are reluctant to talk about (Dyreprov, 2004). So the interviewer was careful not to rush them to answer and wait until they start to talk. The subjects were also informed in advance they could stop talking whenever they wished.

The study was conducted between January and November, 2004. Because of the importance of building rapport between interviewee and interviewer and the need to follow-up on reported experiences, each subject received two semi-structured interviews (Frank, 1984). Mean combined interview length was 125.0 minutes (range : 30 to 255). All interviews were conducted by one of the authors. Semi-structured interviews were con- ducted using an interview guide. The interviewer had a 3-year experience as a pharmacist in pharmaceutical counseling services for cancer patients at the oncology ward in the general hospital. Subjects granted consent for interviews in a variety of locations depending on their physical condition: during IV treatment (chemotherapy or treatment room), while waiting for treatment (conference room), or during a hospital stay (hospital room or conference room).

With permission, most interviews were recorded with MD and IC recorders. Two subjects refused interview recording, but did consent to the taking of detailed interview notes. Reasons cited for refusal were 1) "I don't want a record kept" and 2) [because of my condition] "my voice is so bad that you probably won't understand a recording anyway." Interviewers also prepared field notes immediately following each interview to record their impressions of the subject, their demeanor and expressions, clothing and general appearance, and other relevant information acquired before and after the interview itself.

The initial interview encouraged the subject to speak freely; the second interview made use of information gathered during the first session to facilitate patient-appropriate data collection. Length of time between first and second interviews ranged from two to six months. Four subjects were interviewed only once owing to one death, one severe decline in health and two facility transfers. Nine subjects experienced serious medical decline between interviews with problems including bone fractures and significant pain.

\section{Interview Questions}

To elicit clear information concerning perception of post-recurrence problems, the interviewer inquired about a range of experiences occurring before the initial diagnosis up to the present. The 
same approach was used to create individual patient life-lines. Here the term 'initial diagnosis' is used to differentiate first diagnosis of cancer from subsequent recurrences.

1) Life-Lines and Related Factors

Subjects were asked to draw a retrospective lifeline extending from before initial diagnosis to the present (mean of 26.4 months following recurrence). For the purpose of this study, lifelines are defined as 'tools to express subjective QOL of subjects.' Subjects were instructed to plot their 'psychological state,' as the word 'life' in English is not readily rendered in Japanese (Minami, 1980). This simple, natural phrase was judged to express most closely the concept at issue. Accordingly, subjects were instructed to 'use a line to draw the changes in your psychological state from shortly before you found out you were sick to now.'

A standard $13 \times 26 \mathrm{~cm}(\mathrm{~h} \times \mathrm{w})$ sheet was supplied as the drawing surface, with the vertical axis representing psychological state and the horizontal axis representing time. The vertical axis was ruled at $6.5 \mathrm{~mm}$ intervals such that -10 represented the worst state, 0 neutral, and +10 the best state. The mean length of time represented by the lifelines was 62.2 months.

After viewing a subject's life-line, the interviewer used it as a guide to inquire about reasons for rising or falling patterns and asking specifically about the subject's feelings at certain times, the particular timing of changes, and perceived reasons for those changes. In order to obtain more information about important factors affecting life after recurrence, subjects were also asked about daily pleasures and emotional supports, changes brought about by the cancer (in daily life, world view, and relationships), differences in feelings and experiences between initial diagnosis and diagnosis of recurrence, and economic issues.
During the second interview, subjects drew supplementary life-lines expanding upon the one produced during the initial interview. This life-line covered the time elapsed between interview sessions.

2) $\mathrm{SF}-8$

A modified version of the eight item $\mathrm{SF}-8$ Health Survey (Ware et al., 2001) was used to assess health status at each of the two interviews, changes between these two time-points, and to verify the validity of the life-line methodology. A detailed measure was created for the purpose of assessing slight changes in each question as opposed to measuring overall QOL through total point scores.

\section{Analysis Methods}

A transcript was created for each of the interview recordings. The method of Lofland and Lofland (1995) was used to code and categorize the transcripts over repeated readings.

To confirm the validity of the results analysis of this qualitative study, we employed a technique involving member checks with six patient subjects and peer debriefings with their primary physicians or with other investigators (Creswell, 1998).

Numbers in parentheses within quotes are case numbers which correspond to Table 1.

\section{Ethical Considerations}

This study was reviewed and approved by the Ethics Committees of the participating medical institutions. Personal data was protected by substitution of ID numbers for individual names; all measures were taken to ensure patient privacy.

\section{Results}

\section{Subject Demographics}

Subject demographics are shown in Table 1. Mean age was 52.9 years (range $: 29$ to 74 ). Twen- 
Table 1 Subject Demographics $(n=26)$

\begin{tabular}{|c|c|c|c|c|c|c|c|c|c|c|c|}
\hline \multirow[t]{2}{*}{ Case } & \multirow[t]{2}{*}{ Age } & \multirow[t]{2}{*}{ Spouse } & \multirow[t]{2}{*}{$\begin{array}{l}\text { Children } \\
\text { [minors }]\end{array}$} & \multirow[t]{2}{*}{$\begin{array}{l}\text { Empl- } \\
\text { oyed }\end{array}$} & \multirow[t]{2}{*}{ Type } & \multirow[t]{2}{*}{$\begin{array}{l}\text { Time since } \\
\text { initial } \\
\text { diagnosis }\end{array}$} & \multirow[t]{2}{*}{$\begin{array}{l}\text { Time since } \\
\text { first diagnosis } \\
\text { of relapse }\end{array}$} & \multicolumn{2}{|c|}{$\begin{array}{l}\text { In/ Outpatient } \\
\text { (First or } \\
\text { second } \\
\text { interview) }\end{array}$} & \multirow[t]{2}{*}{$\begin{array}{c}\text { Changes during } \\
\text { study period }\end{array}$} & \multirow[t]{2}{*}{$\begin{array}{l}\text { Life- }^{-} \\
\text {line } \\
\text { group }^{2}\end{array}$} \\
\hline & & & & & & & & $1^{\mathrm{st}}$ & $2^{\text {nd }}$ & & \\
\hline 1 & 68 & Yes & 2 & No & Distant & 3 yrs., 8 mos. & 1 yrs., 4 mos. & Out & In & $\begin{array}{l}\text { Cerebellar } \\
\text { metastases }\end{array}$ & $\mathrm{A}$ \\
\hline 2 & 37 & Yes & $2[2]$ & Yes & Local & 2 yrs. & $1 \mathrm{wk}$. & Out & Out & - & A \\
\hline 3 & 47 & Yes & 2 & No & Distant & 7 yrs. & 2 yrs., 11 mos. & Out & Out & - & $\mathrm{C}$ \\
\hline 4 & 63 & Yes & 3 & Yes & Local & 4 yrs., 4 mos. & 2 yrs., 3 mos. & Out & - & Facility transfer & B \\
\hline 5 & 60 & Yes & 2 & No & Distant & 14 yrs., 8 mos. & 6 yrs., 8 mos. & In & In & Renal metastases & B \\
\hline 6 & 41 & No & 0 & Yes & Distant & 2 yrs., 7 mos. & 1 yr., 9 mos. & Out & In & $\begin{array}{l}\text { Lymph node, } \\
\text { pleural } \\
\text { metastases }\end{array}$ & $\mathrm{A}$ \\
\hline 7 & 49 & Yes & 2 & No & Distant & 1 yrs., 8 mos. & $1 \mathrm{wk}$. & Out & Out & Renal metastases & $\mathrm{C}$ \\
\hline 8 & 54 & Yes & 2 & No & Distant & 2 yrs., 4 mos. & 1 yr., 3 mos. & Out & Out & - & B \\
\hline 9 & 55 & Yes & 2 & Yes & Distant & 2 yrs., 5 mos. & 4 mos. & In & - & Death & - \\
\hline 10 & 73 & Yes & 1 & No & Distant & 7 yrs., 8 mos. & 8 mos. & Out & Out & - & A \\
\hline 11 & 48 & Yes & 2 & Yes & Distant & 1 yrs., 10 mos. & $* 1$ & Out & Out & - & - \\
\hline 12 & 64 & Yes & 2 & No & Distant & 3 yrs., 9 mos. & 1 yrs., 3 mos. & In & Out & - & - \\
\hline 13 & 35 & No & 0 & No & Distant & 6 yrs., 2 mos. & 5 yrs., 2 mos. & In & In & $\begin{array}{l}\text { Cerebral } \\
\text { metastases }\end{array}$ & $\mathrm{C}$ \\
\hline 14 & 60 & Yes & 2 & Yes & Distant & 1 yrs., 11 mos. & 7 mos. & Out & Out & - & - \\
\hline 15 & 64 & No & 4 & No & Distant & 11 mos. & $* 1$ & Out & Out & - & - \\
\hline 16 & 39 & No & 0 & Yes & Distant & 2 yrs., 7 mos. & 1 yrs., 3 mos. & Out & Out & - & A \\
\hline 17 & 44 & Yes & $2[2]$ & Yes & Distant & 5 yrs., 9 mos. & 3 yrs., 8 mos. & Out & In & Increased pain & $\mathrm{C}$ \\
\hline 18 & 38 & Yes & $2[2]$ & Yes & Distant & 14 yrs., 7 mos. & 8 mos. & Out & In & $\begin{array}{l}\text { Residual breast, } \\
\text { lymph node } \\
\text { metastases }\end{array}$ & A \\
\hline 19 & 57 & Yes & 1 & No & Distant & 10 yrs., 2 mos. & 2 yrs., 11 mos. & Out & - & Facility transfer & $\mathrm{C}$ \\
\hline 20 & 64 & Yes & 1 & No & Distant & 4 yrs., 2 mos. & 10 mos. & In & - & $\begin{array}{l}\text { Condition } \\
\text { worsened }\end{array}$ & $\mathrm{C}$ \\
\hline 21 & 74 & No & 0 & No & Distant & 13 yrs., 10 mos. & 8 yrs., 1 mos. & Out & Out & - & B \\
\hline 22 & 48 & No & 0 & No & Distant & 3 yrs., 2 mos. & $* 1$ & Out & Out & Renal metastases & - \\
\hline 23 & 29 & Yes & 0 & $\begin{array}{l}\text { On } \\
\text { leave }\end{array}$ & Distant & 2 yrs., 7 mos. & 1 yrs., 11 mos. & Out & Out & - & $\mathrm{C}$ \\
\hline 24 & 45 & Yes & 0 & No & Distant & 3 yrs., 1 mos. & 2 yrs., 8 mos. & Out & Out & - & $\mathrm{C}$ \\
\hline 25 & 64 & Yes & 3 & No & Distant & 6 yrs. & 1 yrs., 10 mos. & Out & Out & - & $\mathrm{C}$ \\
\hline 26 & 56 & Yes & 2 & No & Distant & 6 yrs. & 3 yrs., 2 mos. & Out & Out & - & $\mathrm{C}$ \\
\hline
\end{tabular}

$1:{ }^{*}$ indicates distant metastases at initial diagnosis

$2:$ Groups as indicated in Figure 1.

ty-three of 26 subjects had experienced recurrence within the past five years ; mean time since recurrence was 26.4 months (range : 1 week to 97 months). At the beginning of the study two subjects had localized recurrence in the thoracic wall or skin and the remaining 24 had distant metastases. Secondary sites identified at the completion of the study included skeletal $(n=15)$, lungs $(n=7)$, brain $(n=5)$, and liver $(n=3)$; some subjects had multiple metastases. All subjects underwent chemotherapy or radiotherapy during the study period. 


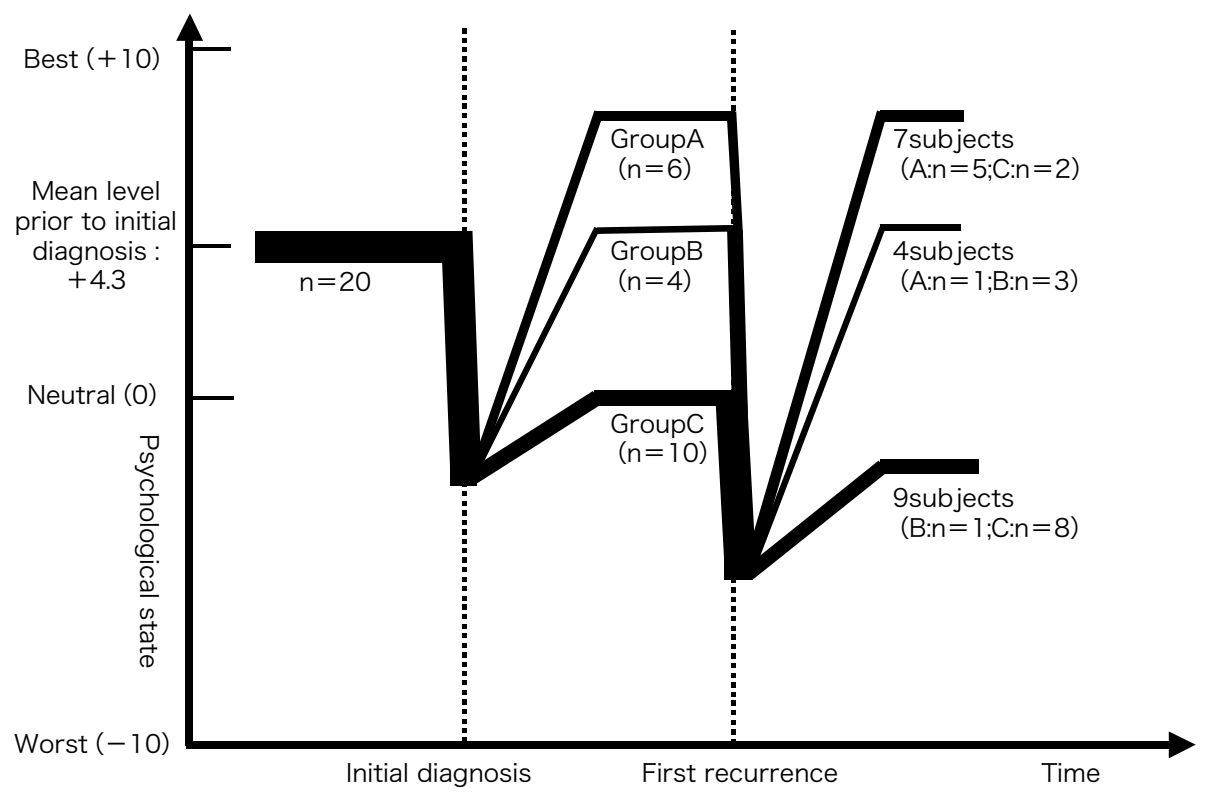

Figure 1 Life-lines patterns and groups from prior to initial diagnosis to just before second episode of recurrence $(n=20)$

\section{Life-Line Patterns}

Figure 1 illustrates the main life-line patterns drawn by the subjects covering the period from before initial diagnosis to just before the second episode of recurrence. Out of 26 subjects, this figure includes 20 subjects. Six were excluded because three had distant metastasis at the initial diagnosis, two had rising life-lines after the first episode of recurrence but the final recovery status was unknown, and one had a life-line which did not cover the period prior to initial diagnosis. In this table, 'recovery' is defined as a post-diagnosis psychological profile equal to or better than that reported by the same subject prior to initial diagnosis.

1) Life-Line Patterns from Before Initial Diagnosis to Following the First Episode of Recurrence

As shown in Figure 1, life-line patterns may be grouped according to response to initial diagnosis and response to recurrence. Group A subjects dis- played exemplary recovery, with post-recurrence levels exceeding that of prior to initial diagnosis ; Group B displayed good recovery, with lines regaining the same level as prior to initial diagnosis; finally, Group C failed to recover, with life-line levels remaining depressed compared to pre-initial diagnosis levels.

Following initial diagnosis but prior to recurrence, Groups A, B, and C contained 6, 4, and 10 members respectively.

Subjects with lower life-lines prior to initial diagnosis tended to exhibit better recovery : pre-diagnosis mean values were -1.2 (range : -10 to +5 ) for Group A, 4.3 (range : 0 to +9 ) for Group B, and 7.5 (range : -3.5 to +10 ) for Group $\mathrm{C}$, with a mean of 4.3 (range : -10 to +10 ) across all groups. Mean ages for these groups were 49.3 (range $: 37$ to 73 ), 62.8 (range $: 54$ to 74 ), and 49.0 (range : 29 to 64 ) respectively.

In an expanded view encompassing the first diagnosis of recurrence, we found that subjects classi- 
fied as either Group A or Group B prior to recurrence continued to fit into the same group following recurrence. Likewise, subjects initially classified as Group C remained in Group C, demonstrating the same difficulty in recovering after both initial diagnosis and diagnosis of recurrence.

Twelve subjects experienced greater declines in life-lines after the first recurrence than after the initial diagnosis, while the reverse was true for seven subjects. Four subjects reported approximately the same level of life-line depression at both points. Of the seven subjects describing greater difficulty of recovery from initial diagnosis than recurrence, four ascribed the reason to becoming accustomed to the idea of disease and treatment before the first recurrence.

2) Life-Line Patterns from Second Recurrence Forward

Nine patients reported two or more instances of disease recurrence up to a maximum of five recurrences. Most subjects demonstrated the same pattern after the second recurrence as before the first, and five out of nine subjects described recovery to the pre-initial diagnosis level even after multiple episodes.

Some subjects experienced loss of physical and economic independence as the result of multiple recurrences. Among this group, life-lines dropped precipitously and remained depressed after all hope of recovery faded. One subject (Case 13) showed a dynamic life-line which rose and fell even after five months of being bed-ridden. This subject reported never losing hope of recovery.

Except for the few patients who experienced difficulty recovering from multiple recurrences, lifeline patterns following second recurrence could be reliably predicted to match the pattern established during the interval between pre-initial diagnosis to first recurrence.

\section{3) SF-8 and Life-Line Comparisons}

Two measurement methodologies of $\mathrm{SF}-8$ and life-lines were used at both interviews. We compared life-lines with $\mathrm{SF}-8$ to investigate the criterion validity of life-lines. Comparison was made by investigating the change in direction between two time points (the first interview (T1) and the second interview (T2)) for life-lines and $\mathrm{SF}-8$.

The level of life-lines and $\mathrm{SF}-8$ at the first interview was defined as LL (T1) and SF-8 (T1) respectively. The level at the second interview was also defined as LL (T2) and SF-8 (T2) in the same manner. We call the movement as "upward" if LL $\quad(\mathrm{T} 1)<\mathrm{LL} \quad(\mathrm{T} 2)$ or $\mathrm{SF}-8 \quad(\mathrm{~T} 1)<\mathrm{SF}-8 \quad(\mathrm{~T} 2)$, and "downward" if LL (T1) >LL (T2) or SF-8 (T1) $>\mathrm{SF}-8$ (T2). For 19 patients, the agreement rate between each domain of $\mathrm{SF}-8$ and life-lines, measured by either upward or downward movement, was calculated and the result was as follows : general health $(\mathrm{GH}): 64.7 \%$, physical functioning $(\mathrm{PF}): 41.2 \%$, role physical (RP) : 64.7\%, role emotional (RE) : $70.6 \%$, bodily pain (BP) : $54.9 \%$, vitality (VT) $: 76.5 \%$, social functioning (SF) : 76.5\%, mental health $(\mathrm{MH}): 76.5 \%$. These results show that the life-lines corresponded more consistently with the mental health domains of the $\mathrm{SF}-8$ than the physical health domains.

More than half of the subjects whose $\mathrm{SF}-8$ and life-line patterns did not agree had life-lines which unchanged (rose) as $\mathrm{SF}-8$ parameters fell (unchanged) : GH : 62.5\%, PF : 50.0\%, RP : $62.5 \%$, RE : 85.7\%, BP : 50.0\%, VT : 50.0\%, $\mathrm{SF}: 66.7 \%$, and $\mathrm{MH}: 50.0 \%$.

\section{Distress Leading to Depressed Post- Recurrence Life-Lines}

Distress in this context may be divided into two categories ; 1) distress related to sickness, treatment, and survival, and ; 2) distress related to the 
significance of life itself and one's reasons for living. The post-recurrence distresses listed below do not differ in nature from those following initial diagnosis, although they did tend to occur with greater frequency and severity.

1) Sickness, Treatment, and Survival

(1)Worsening of condition and awareness of death. This category distresses tended to result in dramatic depression of life-lines. Precipitating factors include :

a) Worsening of condition

- Discovery of additional tumors with diagnosis of recurrence $(n=25)$

b) Loss of hope and awareness of death

- Drug used did not work as hoped; tumors increased in severity $(n=5)$

- Doctors or nurses used language which made subjects aware of approaching death $(n=2)$

(2) Increased physical suffering. Particularly severe pain and impaired independence from restricted physical activity also tended to dramatically depress life-lines. Major forms of increased physical suffering include increased pain from bone metastasis $(\mathrm{n}=15)$, weakness, enervation, and a loss of physical control associated with prolonged treatment and declining health $(\mathrm{n}=16)$, and sideeffects from anticancer agents or radiation therapy such as hair loss, nausea, numbness, or 'fear of physical deterioration.' $(n=7)$

(3) Loss of control and increased uncertainty. Many subjects reported feelings of loss of control with respect to their disease, including anxiety and fear from 'the unknown progression of their illness' $(n=7)$, length of the treatment period $(n=$ 18) ("it never seems to end" (Case 18)), gradually diminishing options for treatment and loss of hope, and the feeling that "I cannot do anything to improve my own condition" (Case 9). Almost all subjects reported becoming overwhelmingly uncertain about the time remaining to them and increas- ingly anxious and uncertain about the disease. These feelings of uncertainty, anxiety, depression, irritability, sadness, and fear of death tended to increase during times of worsened conditions, pain, and when the subject was alone.

2) Life and Reasons for Living

(1) Increased psychological burden, decreased social roles and self-esteem. Most subjects reported difficulty in continuing to fulfill work or house-work because of worsening of condition or treatment side effects. Younger subjects in particular reported economic burden and anxiety about being able to carry on with daily life. The six subjects who were 45 or older were no longer able to fulfill family roles or contribute to society as they wished. Those whose children were still minors experienced sadness at the thought of not being able to care for their children any longer, impatience, and irritability that their role was being disrupted. These subjects also experienced an increased financial burden, diminished self-esteem from loss of physical function and therefore independence $(\mathrm{n}=13)$, and increased awareness that they were burdening their families $(n=10)$.

(2)Diminished interpersonal relations. Subjects reported impaired personal relations as a result of more frequent admittances to the hospital, changes in appearance attributable to side effects, decreased opportunities of leaving the house for health reasons, feeling of estrangement with healthy persons, and increased isolation because of lack of support $(n=15)$.

(3)Decreased pleasures and meaning for living. Subjects reported declining enjoyment of hobbies and pleasures that require going outside or using either physical stamina or refined motor skills. Poor health resulting from the disease, side effects, and the fact of continually changing health status meant that even going shopping became problematic $(n=13)$. Some of these subjects 
reported a loss of goals, dreams, pleasures, as well as difficulty in finding meaning in life.

\section{Methods for Coping with Distress and}

\section{Maintaining/Recovering Life-Lines}

As with distress above, we will discuss methods for coping with distress and maintaining/recovering life-lines in terms of;1) coping strategies related to sickness, treatment, and survival, and ;

2) coping strategies related to the significance of life itself and one's reasons for living.

1) Sickness, Treatment, and Survival

(1) Resignation to living with disease. Subjects described various methods for accepting and actively engaging their own treatment: adjusting lifestyle rhythms $(n=8)$ ("not exerting myself in the first half of the week" (Case 18)), considering treatment their 'job' $(n=4)$, and positively viewing illness and treatment, such as by thinking of communicating with their physician as 'fun' $(n=6)$

Subjects used such language as 'surrendering to,' 'living with', and 'becoming resigned to' their illness $(n=14)$, describing changes in feelings as the result of pain and other subjective symptoms and prolongation of treatment. Some subjects reported a deepened awareness of having cancer following recurrence $(n=4)$ ("I came to grips even more with the fact of having cancer" (Case 25)).

(2)Trusting physicians. Some patients had felt dissatisfaction or anger with their physicians or medical institutions. Ten subjects had switched facilities since initial diagnosis, almost all of whom felt that finding a doctor they could trust was crucial. Most subjects felt that having faith in their physician and being able to trust their explanations, treatment methods, and human side, was a key factor in allowing them to focus on receiving treatment without misgivings.

In particular, subjects described the importance of a physician who was "compatible [with them]"
(Case 16), "listens carefully to what I say" (Case 25), "answers my questions" (Case 6), and "can tell how I want to be handled" (Case 17) in helping to ease their fears so they could confront their illness.

(3)Actively controlling disease and own emotions. Seventeen subjects used methods to actively control their physical condition, either through attempting to slow the course of the disease or suppressing side effects. Methods used included eating healthy foods, gargling, dietary supplements, visualizing cancer cells disappearing, or using pain medications early before pain became too great. Eleven subjects reported at least some success with these methods.

In terms of dealing with anxiety, most subjects reported coping by means of avoidance ("not thinking about it too much" (Case 26)). However, some subjects reported not hiding their condition from those around them, maintaining previous relationships, and actively seeking information as ways of controlling anxiety. Further, although some subjects did mention 'soothing themselves by talking to others,' 15 described the importance of thinking positive thoughts to themselves, including 'doing [their] best' and 'changing [their] moods.' Some subjects described this emotional control as related to rising life-lines.

(Regarding a rising life-line) I don't think there's any reason...any particular reason. The best reason might be...Here I became depressed, and I had help from those around me...I didn't really make an effort per se...I just thought about different things and managed to make it back to this level... (Case 2)

(4) Compare current condition favorably with past conditions or with others. Twelve subjects described a process of consoling themselves by positively comparing their condition with others 
who were in worse condition, by imagining such others, or simply imagining scenarios which made their current one seem preferable $(n=12)$ : ("I'm blessed” (Case 25), "I'm lucky” (Case 11)). Six subjects reported some feeling of consolation by realizing that 'it wasn't just [them]'.

When I think that if I hadn't gone to the hospital then, I might have already been dead...That's such a bracing thought...This past month I've been thinking about that and trying to live whole-heartedly... (Case 16)

(5) Maintaining hope in the future. For the duration of the study, all subjects were receiving some form of ongoing treatment. Definitions of hope varied considerably, even among individual subjects, depending on advancement in their disease. A single patient could express over time a range of comments including, 'I want to get better,' 'I want to have many treatment options,' 'I just want to maintain my current state,' and 'I just want to be free from pain.' Interestingly, even those who were pessimistic shortly after being told of a recurrence indicated some faith in medical progress $(n=2)$ as they continued treatment ("I see the light at the end of the tunnel" (Case 2)). Some expressed hope in new drug development $(n=8)$, wishing to live long enough to benefit. For those holding this view, such hope in treatment advances corresponded to a rise or at least maintenance of life-lines. On the other hand, subjects who had undergone prolonged treatment, attempted multiple treatment methods, or felt that few options remained, showed gradual or sharp declines in their life-lines ; in many cases, depressed lifelines rebounded unless the subject lost all hope in recovery.

2) Life and Reasons for Living

(1)Living a meaningful life. Most subjects described an approach that involved suppressing worry about their illness and the future and avoiding mental and physical burdens ( 'housework' and 'stress from interpersonal relations') ; they also emphasized 'being positive and relaxed' and 'enjoying each day.'

Twelve subjects described a growing ability to find satisfaction and contentment through greater enjoyment of very small aspects of daily life in addition to traveling or leaving their homes. This adaptation was associated with rising life-lines in six subjects. Case 10 described the great pleasure derived from making artificial flowers, an old hobby that she took up again after surgery following her initial diagnosis.

I try to think about negative, bad things as little as I can. Instead, when I handle beautiful things, nature, or when I look at the pretty, gentle flowers in a finished piece, I just become happy and glad. I just smile naturally, even all by myself. (Case 10)

Seventeen subjects reported feelings of peace or happiness through daily prayer or contact with children, nature, or animals. Also, 10 subjects reported receiving positive feelings and "happiness" from the normal daily life of their family and the sight of things going well for those around them.

When my family gets together, we end up talking about my sickness and the mood gets very dark. When there is a baby around, though, he becomes the focus of attention, and the mood brightens for the whole family. Thus my nephew is very important. (Case 16)

(2)Living for oneself. Four subjects described a scaling back of previous goals related to work, volunteering, and child-rearing in order to make 
them easier to accomplish ("I asked for a change of position at work that would give me an easier job I could feel more positive about" (Case 16)). Five subjects reported 'wanting to live according to their own criteria,' ("as long as I'm satisfied" (Case 25)).

Four subjects described how contact with other breast cancer patients made them want to seek new opportunities to help others ("I want to lend my help to someone who needs it" (Case 23)).

(3)Experiencing growth. Thirteen subjects reported feeling that they had experienced personal growth: 'I have gained something from becoming sick,' 'I've become stronger,' '[I've gained] confidence.' Interestingly, in four of these cases growth was perceived after the challenges of recurrence and not after initial diagnosis. Case 2 describes the role a certain book played in allowing her to gain confidence, resulting in a rise in her life-line :

I had been thinking about what it means to live, but had not been able to organize my thoughts very well. When I read that, though, I felt much clearer '.I think I've been able to change, which is a good thing. If you don't sing your own praises, after all. I finally realized that everything, everything I'd been thinking, was OK. (Case 2)

\section{(4)Increased importance on social relation-} ships. Nineteen subjects reported a change in interpersonal feelings such as increased 'gratitude towards others' or 'more interest in others.' Most of these subjects reported receiving increased support from others as their condition declined, including thoughtful gestures like being given food.

Everyone deals with their feelings on such a surface-level $\cdots$ I try to listen really hard, not just let things pass, when people talk about their true feelings. (Case 19)

Many subjects reported 'thinking only about the illness' or 'being aware of being sick all the more' when alone. Maintaining a job and chores helps increase contact with society and helps build confidence.

People often ask me if I'm alright, working even though I'm so sick. But, the truth is being sick means I can't stand being cooped up at home. I've been like that ever since I first got sick. (Case 2)

Patients derived support from contexts in which they could air anxiety, frustration, and similar emotions with acceptance. For most subjects these contexts were family or doctor, but some subjects 'did not want to worry their family,' so they were left without an outlet for this kind of expression.

Two subjects reported regularly visiting therapeutic hot springs for rest therapy. Five subjects met fellow patients or groups of patients either in their hospitals or over the Internet. Several subjects described the emotional support derived from meeting with fellow patients who had 'a similar worldview' ("They listen to my complaints the way my family won't" (Case 23), "We can share because we have the same sickness" (Case 3)).

(5)Leaving behind proof of having lived. Four subjects reported "wanting to leave something behind" (Case 23). Generally this desire consisted of creating something only they could do, such as a personal work of art, or providing a description of their work for those who would take it over. Three of these subjects experienced this change following recurrence. 


\section{Discussion}

\section{Positioning of Breast Cancer Patients and Life-Lines in the Current Study}

Inclusion in the present study specified a minimum six month life expectancy based on the judgment of the patient's primary physician. Only seven of 26 subjects died within the first 11 months of the study. Unsurprisingly, the general health of study subjects during this period trended toward decline. However, the life-lines obtained spanned the period from before initial diagnosis, through recurrence and progression, to immediately before the terminal period. Therefore, within the context of the trajectory framework often used to describe the experience of chronic illness, subjects in this study were chiefly grouped at the lower terminus of that trajectory (Woog, 1992). On an 8 trajectory phases ranging from 1 (Pre-trajectory) to 8 (Dying phase), most fell into categories 6 (Unstable phase) and 7 (Downward phase). Results from this study should serve as a valuable resource for providing support services for patients in this condition, as well as a useful guide for future studies.

Although different trends were observed in Groups A-C (Fig. 1), the fact that pre-initial diagnosis life-line levels differ according to each group is thought to reflect the subjective nature of the measurement, wherein each person views their pre-diagnosis life differently according to their current status.

\section{Life-Line Validity}

Two methodologies of life-lines and an eightitem health-related QOL questionnaire based on the $\mathrm{SF}-8$ were used at two timepoints for each subject. Comparison of the two reveals a greater consistency of life-lines with the mental health domains of the SF- 8 than with the physical health domains, suggesting that life-lines are primarily suited to assessment of psychological status. In view of the instructions given to subjects to map their 'psychological state,' this finding supports the validity of the life-line methodology when examined in conjunction with interview data. Life-lines appear to holistically reflect a diverse array of patient attributes including physical health, life roles, mental health, hope, and the significance of life itself. Importantly, the research literature also confirms relationships between life-line trends and averages and emotions about life (Martin, 1997), overall health state (Ringsberg et al., 2001), life satisfaction (Back and Averett, 1985) and finding meaning in life (Takkinen and Ruoppila, 2001). Although the range of attributes measured in the present study are very broad, the results tend to support its validity.

\section{Mechanisms of Life-Line Recovery}

In most cases relapsed breast cancer results in progressive health decline and ultimate death. It is therefore remarkable that the life-lines of about half of the subjects demonstrated significant resilience. Not only did about half subjects regain a pre-initial diagnosis level of psychosocial equanimity ; some exceeded that level.

Interview data show that cognitive coping, or the way in which an individual comes to terms with the original cause of the decline, is an important factor influencing a rise in an individual's lifeline following an earlier decline. This coping process can be considered equivalent to the phenomenon of the response shift, or the change in an individual's own standards for assessing her QOL (Sprangers and Schwartz, 1999). This response shift represents a recalibration of internal standards, a change in values, or a reconceptualization based on subjective social comparison (Gibbons, 1999), meaning-based coping (Richards and Folk- 
man, 2000), reframing expectations (Allison et al., 1997), or goal reordering (Rapkin and Fischer, 1992) in response to change of health status. Past researches demonstrate that this response shift is a key component in $\mathrm{QOL}$ recovery and improvement.

Cognitive coping as exemplified by the response shift described above is a core component of the life-line recovery and maintenance observed in this study. Further qualitative studies are required to elucidate the detailed mechanisms through which cognitive coping occurs, as well as the circumstances that trigger such mechanisms.

\section{Factors with Positive Effect on Life- Lines}

Results suggest that there are two main factors contributing to elevated post-recurrence life-line patterns. These include 1) the ability to summon the desire or energy required to maintain hope with a possibility of overcoming and surviving cancer and 2) the discovery of sense of meaning in life, usually defined as an ability to experience peace or joy. Factors that contribute to a tranquil psychological state may include appreciation of daily pleasures and/or the wonders of nature, satisfaction derived from service to others and gratitude for the gift of life. Patients who integrated either of the above two strategies into their lives after relapse tended to exhibit life-line maintenance or recovery.

Generally, the former strategy falls into the category of sickness, treatment, and survival and is most important after initial diagnosis and before recurrence (Stanton et al., 2002). In contrast, the latter mental attitude is a result of cognitive coping that occurs in the realm of life and reasons for living, and thus plays an important role in easing the psychological state of patients in the terminal phase (Yeung et al., 1999). Relapsed subjects in the cur- rent study appeared to combine characteristics of patients in both treatment and terminal stages.

The significance of hope for cancer patients has been studied previously in several contexts, including patients experiencing relapse (Cella et al., 1990), patients in the treatment phases of advanced cancer (Luoma and Hakamies-Blomqvist, 2004), and during the terminal phase (Herth, 1990). In the current study hope is defined as "the subjective probability of a good outcome" (Little and Sayers, 2004). Most manifestations of hope are related to an expectation of survival or improvement, sustained by continuation of some form of treatment. This observation is consistent with recognized patient psychology in which continuation of treatment, even in relapsed patients with no hope for cure, is undertaken to achieve modified goals including improved physical or affective function (Luoma and Hakamies-Blomqvist, 2004).

In this study, the definition of hope was observed to change according to the vicissitudes of individual patient circumstances. Some subjects forestalled psychological despair with a positive outlook ('I don't need to be cured; I just don't want to get worse.') This observation is consistent with the phenomenon reported by Little and Sayers (2004) in which the form and object of hope is modified in the evolving search for meaning.

The importance of finding meaning as a method of coping with loss or serious illness is addressed in earlier research (Richards and Folkman, 2000). Changing standards for measuring life satisfaction can be considered a form of cognitive coping. This includes forms of meaning making discussed above. However, the effects of meaning contained within these experiences on QOL and mental health have not been well studied.

To address that deficiency, this paper supports the findings of recent experimental studies clarify- 
ing the roles played by QOL and mental health studies in the construction of meaning in individuals recovering from or adapting to life-threatening illnesses including cancer (Fife, 2005). The importance of finding and characterizing individually constructed visions of meaning is undeniable. Such constructs significantly moderate feelings of despair in terminal cancer patients and promote gradual reconciliation with the disease and its ultimate outcome (McClain et al., 2003).

Understanding those constructs will only improve the design and delivery of compassionate support strategies for patients with incurable cancer.

Related studies have been mostly conducted in Western countries in the past. The finding from our study for Japanese recurrent breast cancer patients shows similar results to those studies. Therefore, we believe there is commonality in the basic human response to the trauma of life-threatening situations, regardless of cultural differences.

\section{Implications}

This study has three major implications :

Primarily, this study is the first to combine patient interviews with life-line methodology to explore relatively unstudied aspects of the emotional lives of post-recurrence breast cancer patients. Results suggest that this technique is useful both to elucidate psychosocial characteristics of post-recurrence breast cancer patients and to facilitate development of improved support systems for them.

Secondly, the life-line technique is shown to help identify key factors that prevent or modify depressed life-lines; such factors include maintenance of hope and cognitive coping mechanisms such as changing standards of QOL measurement. Relapsed patients with few remaining treatment options are extremely prone to lose all hope.
Accordingly, there is a need for developing more effective ways of communicating with these patients. The life-line technique is a valuable tool for uncovering what kinds of information such patients desire and for anticipating how they will react to it. However, more study is needed to better understand the cognitive coping mechanisms observed in this study, especially as they relate to strategies for improving patient QOL.

Finally, there are implications for the life-line methodology itself. In this study, life-lines were used to obtain data about patient experiences based on a consistent internal standard but separated by significant spans of time. Thus, information about changes in subjects' perceived change, or their change of viewpoint over time, was obtained. Life-lines are therefore valuable tools to help medical personnel understand the experiences of individual patients during the course of their illness ; they can also help spur patient selfunderstanding. Because the life-line method is simple and easy to implement, it is an especially practical tool.

When reflecting upon to the life-line process, subjects used phrases such as "I learned about myself" or "I re-assessed my own feelings." This is consistent with observations that, when individuals try to recall their long-term experience with a disease, the retrospective self-evaluation integral to the process promotes new insights. This makes it possible for them to construct unified narratives making sense of what was previously a very chaotic period (Gramling and Carr, 2004). This technique is similar to the life review method (Lewis and Butler, 1974), a clinical exercise with similar aims in which a patient and physician jointly recall and summarize that patient's life to promote selfintegration (Pickrel, 1989 ; Settersten and Mayer, 1997 ; Vaughan and Kinnier, 1996). Although pioneered for use with psychotherapy with geriatric 
patients, the life review method is now being used experimentally with terminal and HIV patients as a psychological intervention technique (Pickrel, 1989 ; Vaughan and Kinnier, 1996). The technique has yet to be applied to cancer patients.

The multiple types of distress elucidated in this study related to both sickness and life in general exposes the lack of an effective support structure for patients with relapsed breast cancer in both medical and general social contexts in Japan. The fact that breast cancer can recur even in young patients and that it is generally incurable underscores the urgency for constructing support structures for patients facing death. Because recurrent breast cancer affects a wide range of age groups with diverse backgrounds and individual circumstances, an effective support system must be sufficiently flexible to respond to individual needs.

\section{Study Limitations and Future Challenges}

The study encompasses several limitations. Subject recruitment was limited to two facilities in Tokyo, both of which offered advanced care. In the future a more diverse array of medical facilities need to be included. It may also be assumed that subjects recommended for the study by their physicians did not include those with the most serious physical or mental problems. A wider array of subjects will help eliminate selection bias and make results valid for a greater patient population.

Also, temperamental factors such as personality (Costa et al., 1996), optimism (Scheier et al., 1989), and sense of coherence (SOC) (Antonovsky, 1987) were thought related to the process of coping with the stresses covered in the current study, but these were not studied. Further study of the subject should also be grounded in this theory.

\section{Conclusion}

The following conclusions were drawn based upon the results of semi-structured interviews with relapsed breast cancer patients :

1. Following their initial diagnosis of breast cancer, approximately half of our subjects exhibited life-line recovery at least equivalent to their pre-initial diagnosis levels. Similarly, approximately half of patients exhibited recovery following first recurrence. However, life-line recovery occurred with diminishing frequency with subsequent relapses.

2. Relapsed breast cancer patients exhibited greater life-related distresses than initial diagnosis patients. These distresses included worsening physical condition, a greater awareness of death and sense of uncertainty, a decline in social relationships and pleasures, and a declining ability to find meaning in living.

3. A cognitive coping process equivalent to a response shift, or changes in an individual's own standards for viewing her life, emerges as a factor influencing life-line recovery.

4. The life-line methodology did reflect results from the $\mathrm{SF}-8$ questionnaire. However, those similarities were more consistent with the mental health domains of the $\mathrm{SF}-8$ than the physical health domains.

5. Life-lines of post-recurrent breast cancer patients included coping characteristics demonstrated by both treatment and terminal phase cancer patients.

Study methods provide a useful tool for discerning individual coping profiles. Study results reinforce the recognition that relapsed breast cancer patients have an unmet need for support systems tailored to respond to their individual psychological, spiritual and socioeconomic characteristics and circumstances. 


\section{Acknowledgements}

We would like to thank all patients who participated in this research at the University of Tokyo Hospital and Mitsui Memorial Hospital and Dr. Atsushi Fukuuchi for his help in conducting the survey. We are also grateful to two anonymous referees for their helpful comments on earlier drafts of this paper. Assistance was provided by the Sasakawa Health Science Foundation, who assisted this research in the form of a 2004 Research Grant to Promote QOL in Terminal Care Medicine. Further assistance was provided by a 2002 Basic Research Grant (A) from the Japanese Ministry of Education, Culture, Sports, Science and Technology (No. 14201021).

\section{References}

Allison PJ, Locker D and Feine JS (1997) : Quality of life : A dynamic construct, Soc Sci Med, 45, 221-230

Antonovsky A (1987): Unraveling the Mystery of Health : How people manage stress and stay well, Jossey Bass (San Francisco)

Back KW and Averett CP (1985) : Stability and change in life graph types, Palmore E, Busse E, Maddox GL et al. eds., Normal Aging III : Reports from the Duke Longitudinal Studies 1975-1984, Duke University Press (Durham)

Beaton SR (1991): Styles of reminiscence and ego development of older women residing in long-term care setting, Int J Aging Hum Dev, 32, 53-63

Belcher AE, Dettmore D and Holzemer SP (1989): Spirituality and sense of well-being in persons with AIDS, Holist Nurs Pract, 3, 16-25

Blane DB (1996) : Collecting retrospective data: Development of a reliable method and a pilot study of its use, Soc Sci Med, 42, 751-757

Bull AA, Meyerowitz BE, Hart S et al. (1999) : Quality of life in women with recurrent breast cancer, Breast Cancer Res Treat, 54, 47-57

Burnet K and Robinson L (2000) : Psychosocial impact of recurrent cancer, Eur J Oncol Nurs, 4, 29-38

Cella DF, Mahon SM and Donovan MI (1990) : Cancer recurrence as a traumatic event, Behav Med, 16, 1522

Costa PT Jr, Somefield MR and McCrae RR (1996) :
Personality and coping : A reconceptualization, Zeidner M and Endler NS eds., Handbook of Coping : Theory, Research, Applications, 44-61, Wiley (New York)

Creswell JW (1998) : Qualitative Inquiry and Research Design : Choosing among five traditions, Sage (Thousand Oaks)

Dyreprov K (2004) : Bereaved parents' experience of research participation, Soc Sci Med, 58, 391-400

Fife BL (2005): The role of constructed meaning in adaptation to the onset of life-threatening illness, Soc Sci Med, 61, 2132-2143

Frank G (1984) : Life history model of adaptation to disability : The case of a "congenital amputee", Soc Sci Med, 19, 639-645

Gibbons FX (1999) : Social comparison as a mediator of response shift, Soc Sci Med, 48, 1517-1530

Gramling LF and Carr RL (2004) : Lifelines : A life history methodology, Nurs Res, 53, 207-210

Herth K (1990) : Fostering hope in terminally-ill people, J Adv Nurs, 15, 1250-1259

Jenks JM (1995): New generation research approaches, Streubert HJ and Carpenter DR eds., Qualitative Research in Nursing: Advancing the humanistic imperative, 242-268, Lippincott (Philadelphia)

Kvale S (1996) : Interviews : An introduction to qualitative research interviewing, Sage (Thousand Oaks)

Lawton MP (1991) : A multidimensional view of quality of life in frail elderly, Birren JE ed., The Concept and Measurement of Quality of Life in Frail Elderly, 427, Academic Press (San Diego)

Lewis MI and Butler RN(1974) : Life-review therapy : Putting memories to work in individual and group psychotherapy, Geriatrics, 29, 165-173

Little M and Sayers E-J (2004) : While there's life... hope and the experience of cancer, Soc Sci Med, 59, 1329-1337

Lofland L and Lofland LH (1995) : Analyzing Social Settings : A guide to qualitative observation and analysis, Wadsworth (Belmont)

Luoma M and Hakamies-Blomqvist L (2004) : The meaning of quality of life in patients being treated for advanced breast cancer: A qualitative study, Psychooncology, 13, 729-739

Mahon SM and Casperson D (1997) : Exploring the psychosocial meaning of recurrent cancer : A descriptive study, Cancer Nurs, 20, 178-186

Mahon SM, Cella DF and Donovan MI (1990) : Psychosocial adjustment to recurrent cancer, Oncol Nurs Forum, 17, 47-52 
Martin E (1997) : The symbolic graphic life-line : Integrating the past and present through graphic imagery, Art Ther : JAM Art Ther Assoc, 14, 261-267

McClain CS, Rosenfeld B and Breitbart W (2003) : Effect of spiritual well-being on end-of-life despair in terminally-ill cancer patients, Lancet, 361, 16031607

Minami H (1980) : An overview of quality of life ; Its background and methodological issues, Nihon hoken iryo kodo kagakukai nennpo (The Japanese Journal of Health Behavioral Science), 3, 1-14 (in Japanese)

Ministry of Health, Labour and Welfare (2005) : Jinko Dotai Tokei 2004 (Vital statistics 2004), Ministry of Health, Labour and Welfare (Tokyo) (in Japanese)

Morse JM and Field PA (1995) : Qualitative Research Methods for Health Professionals, 2nd ed., Sage (Thousand Oaks)

Oh S, Heflin L, Meyerowitz BE et al. (2004) : Quality of life of breast cancer survivors after a recurrence : A follow-up study, Breast Cancer Res Treat, 87, 4557

Pickrel J (1989) : "Tell me your story" : Using life review in counseling the terminally ill, Death Stud, 13, 127-135

Rapkin BD and Fischer K (1992) : Framing the construct of life satisfaction in terms of older adults'personal goals, Psychol Aging, 7, 138-149

Richards TA and Folkman S (2000) : Response shift : A coping perspective, Schwartz CE and Sprangers MAG eds., Adaptation to Changing Health : Response shift in quality-of-life research, 25-36, American Psychological Association (Washington DC)

Ringsberg KC, Alexanderson KAE, Borg $\mathrm{KE}$ et al. (2001) : The health-line, a method for collecting data on self-rated health over time : A pilot study, Scand J Public Health, 29, 233-239

Scheier MF, Magovern J, Abbott RA et al. (1989) : Dispositional optimism and recovery from coronary artery bypass surgery: The beneficial effects of physical and psychological well-being, J Pers Soc Psychol, 57, 1024-1040
Schnipper HH (2001) : Life after breast cancer, J Clin Oncol, 19, 3581-3584

Schroots JJF (1996) : The fractal structure of lives : Continuity and discontinuity in autobiography, Birren JE, Kenyan GM, Ruth J-E et al. eds., Aging and Biography : Explorations in adult development, 117-130, Springer (New York)

Settersten RA Jr and Mayer KU (1997) : The measurement of age, age structuring, and the life course, Annu Rev Sociol, 23, 233-261

Sprangers MAG and Schwartz CE (1999) : Integrating response shift into health-related quality of life research : A theoretical model, Soc Sci Med, 48, 1507-1515

Stanton AL, Danoff-Burg S and Huggins ME (2002) : The first year after breast cancer diagnosis : Hope and coping strategies as predictors of adjustment, Psychooncology, 11, 93-102

Takkinen S and Ruoppila I (2001) : Meaning in life as an important component of functioning in old age, Int J Aging Hum Dev, 53, 211-231

The Research Group for Population-based Cancer Registration in Japan (2004) : Cancer incidence and incidence rates in Japan in 1999 : Estimates based on data from 11 population-based cancer registries, Jpn J Clin Oncol, 34, 352-356

Vaughan SM and Kinnier RT (1996) : Psychological effects of a life review intervention for persons with HIV disease, J Couns Dev, 75, 115-123

Ware JE, Kosinski M, Dewey JE et al. (2001) : How to Score and Interpret Single-item Health Status Measures : A manual for Users of the $\mathrm{SF}-8^{\mathrm{TM}}$ health survey, QualityMetric Incorporated (Lincon)

Woog P (1992) : A Nursing model for Chronic Illness Management Based upon the Trajectory Framework, Springer (New York)

Yeung EW, French $\mathrm{P}$ and Leing AO (1999) : The impact of hospice inpatient care on quality of life of patients terminally ill with cancer, Cancer Nurs, 22, 350-357

(Received 3.2.2008; Accepted 7.28.2008) 